\title{
Post-Assembly Atomic Layer Deposition of Ultrathin Metal-Oxide Coatings Enhances the Performance of an Organic Dye-Sensitized Solar Cell by Suppressing Dye Aggregation
}

Ho-Jin Son, ${ }^{*}, \dagger, \S, \otimes$ Chul Hoon Kim, ${ }^{\dagger, \perp, \otimes}$ Dong Wook Kim, ${ }^{\dagger}$ Nak Cheon Jeong, ${ }^{\dagger, \|}$ Chaiya Prasittichai, ${ }^{\dagger,+}$ Langli Luo, ${ }^{\ddagger}$ Jinsong Wu, ${ }^{\ddagger}$ Omar K. Farha, ${ }^{\dagger, \#}$ Michael R. Wasielewski, ${ }^{\dagger}$ and Joseph T. Hupp* ${ }^{\dagger}$

${ }^{\dagger}$ Department of Chemistry, Northwestern University, Evanston, Illinois 60208, United States

${ }^{\ddagger}$ Department of Materials Science and Engineering, NUANCE Center, Northwestern University, Evanston, Illinois 60208, United States

${ }^{\S}$ Department of Advanced Materials Chemistry, Korea University, Sejong 339-700, Korea

"Department of Emerging Materials Science, DGIST, Daegu 711-873, Korea

${ }^{\#}$ King Abdulaziz University, Faculty of Science, Department of Chemistry, Jeddah, Saudi Arabia

\section{Supporting Information}

ABSTRACT: Dye aggregation and concomitant reduction of dye excited-state lifetimes and electron-injection yields constitute a significant mechanism for diminution of light-to-electrical energy conversion efficiencies in many dye-sensitized solar cells (DSCs). For $\mathrm{TiO}_{2}$-based DSCs prepared with an archetypal donor-acceptor organic dye, (E)-2-cyano-3- $\left(5^{\prime}-\left(5^{\prime \prime}-(p-\right.\right.$ (diphenylamino)phenyl)-thiophen- $2^{\prime \prime}$-yl)thiophen-2'-yl)acrylic acid (OrgD), we find, in part via ultrafast spectroscopy measurements, that postdye-adsorption atomic layer deposition (ALD) of ultrathin layers of either $\mathrm{TiO}_{2}$ or $\mathrm{Al}_{2} \mathrm{O}_{3}$ effectively reverses residual aggregation. Notably, the ALD treatment is significantly more effective than the widely used aggregationinhibiting coadsorbent, chenodeoxycholic acid. Primarily because of reversal of OrgD aggregation, and resulting improved injection yields, ALD post-treatment engenders a 30+\% increase in overall energy conversion efficiency. A secondary contributor to increased currents and efficiencies is an ALD-induced attenuation of the rate of interception of injected electrons, resulting in slightly more efficient charge collection.

KEYWORDS: dye-sensitized solar cells (DSCs), atomic layer deposition (ALD), dye aggregation, post-treatment, interfacial electron injection
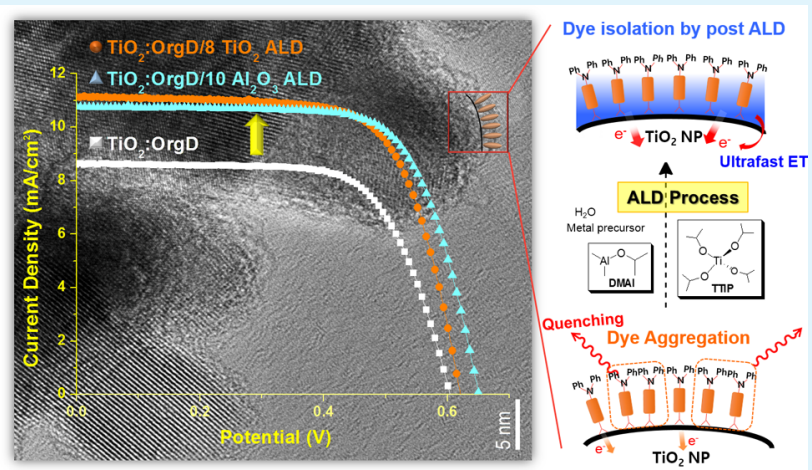

\section{INTRODUCTION}

Due to their chemical versatility and potentially low manufacturing and materials costs, dye-sensitized (moleculesensitized) solar cells (DSCs) are among the most promising third-generation photovoltaic technologies. ${ }^{1-5}$ Impressive photovoltaic performance has been obtained using a variety of organic dyes, with the most highly efficient cells reaching $12+\%$ (and ca. $13 \%$ at 0.1 sun) when pairs of dyes are used together with a carefully designed cobalt-based redox shuttle. $^{6-10}$ Recent work on DSCs has focused, in part, on attaining long-term stability, an essential requirements for broad commercialization. Stabilization strategies have included dye modification (derivatization), ${ }^{11,12}$ alternative dye anchoring chemistry, ${ }^{13-20}$ adsorbed-dye encapsulation by polymer, ${ }^{21-23}$ silica, ${ }^{24}$ or atomic layer deposition (ALD), ${ }^{25-27}$ and introduction of new types of electrolyte (mainly solidification of redox electrolytes). ${ }^{28-30}$
We have recently reported that detachment of metal-oxidebound chromophores, which is one of the challenges to longterm operation of solution-containing DSCs, ${ }^{31}$ can be greatly inhibited by growing, via $\mathrm{ALD}$, an ultrathin transparent metaloxide coating (e.g., $\mathrm{TiO}_{2}$ ) on photoelectrodes that are already dye loaded. ${ }^{32}$ In addition to imparting stability, we discovered that the ALD post-treatment enhances energy-conversion efficiencies, but did not further explore the phenomenon in our initial report. In earlier work ${ }^{24}$ we observed nominally similar behavior (efficiency improvement) following glass $\left(\mathrm{SiO}_{2}\right)$ encapsulation of adsorbed dyes via an ALD-like growth process. ${ }^{33}$ We found that dye-electrode modification with silica boosts overall energy conversion efficiencies mainly by

Received: October 24, 2014

Accepted: February 19, 2015

Published: February 19, 2015 
Scheme 1. Schematic Diagram Depicting Post ALD Process onto Dye-Sensitizing $\mathrm{TiO}_{2} \mathrm{Nanoparticles}^{a}$
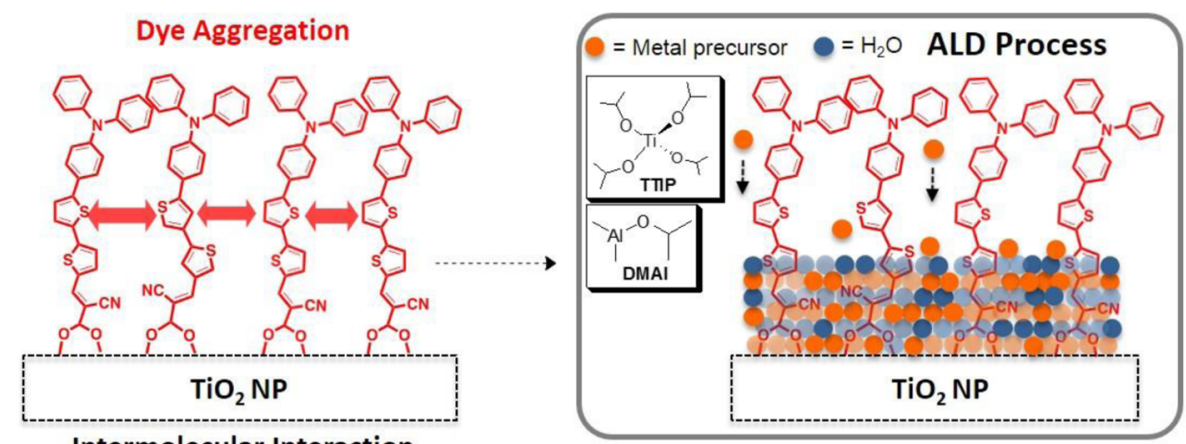

Dye Isolation by post ALD layer

Intermolecular Interaction

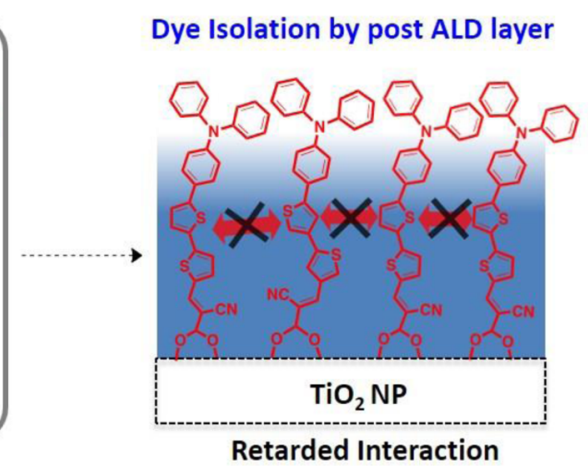

${ }^{a_{T}}$ The alternating metal-oxygen layering shown in the center panel is meant only to communicate the basis for metal-oxide growth by ALD and is not meant to imply crystallinity or even sort-range ordering. Indeed, the ALD coatings appear to be amorphous.

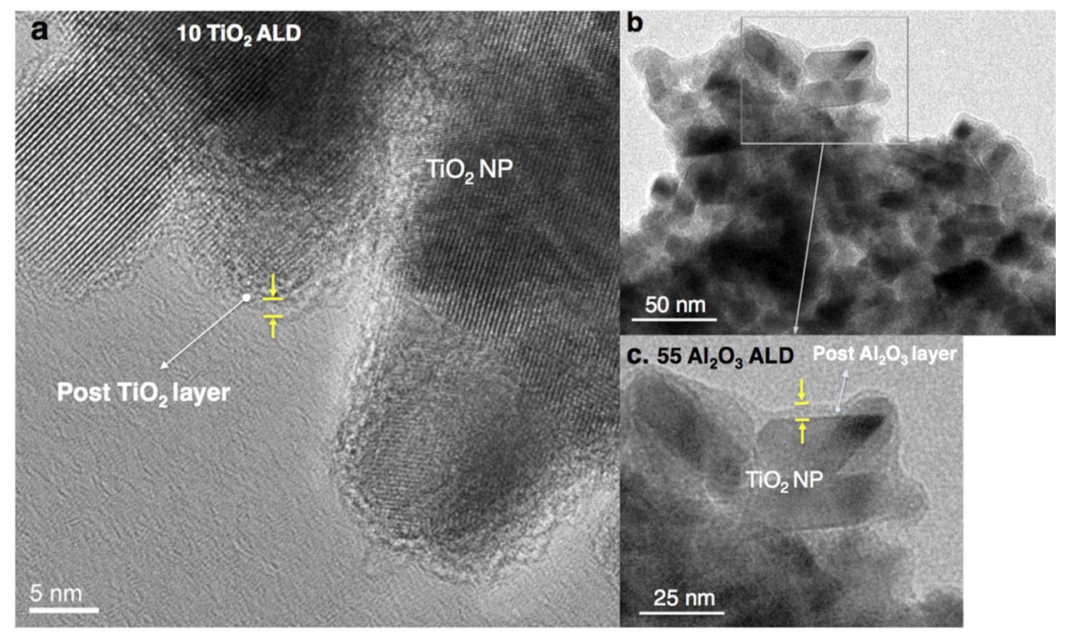

Figure 1. TEM images of (a) $\mathrm{TiO}_{2}: \mathrm{OrgD} / 10$ numbers of $\mathrm{TiO}_{2} \mathrm{ALD}$ cycles (left), (b) $\mathrm{TiO}_{2}: \mathrm{OrgD} / 55$ numbers of $\mathrm{Al}_{2} \mathrm{O}_{3} \mathrm{ALD}$ cycles, and (c) the enlarged view. Note that these results were included, in part, in the Supporting Information of a previous report from our laboratories (ref 32 ).

inhibiting interception of injected electrons by the oxidized form of the redox shuttle and thereby substantially increasing charge-collection lengths and yields. We initially thought that the efficiency improvements observed following postdyeadsorption ALD of $\mathrm{TiO}_{2}$ ("post-ALD") could be similarly explained. To our surprise, electron interception dynamics and charge-collection lengths were only slightly affected by postALD. Consequently, we sought other explanations.

As shown here and elsewhere, ${ }^{32}$ the gaps between preadsorbed dye molecules on standard nanoparticulate $\mathrm{TiO}_{2}$ photoelectrodes can be efficiently filled by post-ALD of either alumina or titania (Scheme 1). Photoelectrochemical and photophysical studies of real and model systems described herein reveal that a) post-ALD treatments boost energyconversion efficiencies primarily by increasing DSC chargeinjection yields, $\eta_{\text {inj }}$, and $\mathrm{b}$ ) the increases in $\eta_{\text {inj }}$ are achieved by eliminating residual dye aggregation and associated ultrafast dye (aggregate) excited-state relaxation processes. A secondary contributor to increased currents and efficiencies is an ALDinduced attenuation of the rate of interception of injected electrons by the oxidized form of the redox shuttle, resulting in slightly more efficient charge collection.

\section{EXPERIMENTAL SECTION}

Atomic Layer Deposition (ALD) Post-Treatment. OrgDloaded $\mathrm{TiO}_{2}$ electrodes were transferred to the reaction chamber of an ALD tool (Savannah 100, Cambridge Nanotech, Inc.) for conformal post-ALD of either $\mathrm{TiO}_{2}$ at $110{ }^{\circ} \mathrm{C}$ or $\mathrm{Al}_{2} \mathrm{O}_{3}$ at $150{ }^{\circ} \mathrm{C}$. Alternating pulses of the precursors titanium(IV) tetraisopropoxide (TTIP, STREM), ${ }^{32}$ or dimethylaluminum iso-propoxide (DMAI, STREM), ${ }^{34}$ and $\mathrm{H}_{2} \mathrm{O}$ were used, with reaction exposure times of 8 $\mathrm{s}$, and with $30 \mathrm{~s}$ of nitrogen flow between reactant pulses.

Time-Resolved Fluorescence (TRF) Spectroscopy. The light source was a home-built cavity-dumped Ti:sapphire laser. The center wavelength and spectral width of the laser were 830 and $55 \mathrm{~nm}$, respectively. Pulse duration was about 25 fs. The cavity-dumping provided about $30 \mathrm{~nJ}$ energy at a $820 \mathrm{kHz}$ repetition rate. Second harmonic generation in a $200 \mu \mathrm{m}$ thick lithium triborate (LBO) crystal generated the pump pulses at $415 \mathrm{~nm}$, and the remaining fundamental served as gate pulses in femtosecond time-resolved fluorescence experiments.

Femtosecond TRF measurements were made using the fluorescence up-conversion technique. The up-conversion apparatus delivered sub50 fs time resolution by utilizing a noncollinear sum frequency generation (SFG) scheme as has been described in detail elsewhere. $^{35,36}$ The SFG was carried out in a $500 \mu \mathrm{m}$ thick $\beta$-barium borate crystal with an external angle of $20^{\circ}$. The cross correlation between the pump and gate pulses was 100 fs. Samples were mounted on a homemade shaking stage to minimize photodamage. All experiments were carried out at ambient temperature.

Steady-state fluorescence and picosecond TRF measurements were made using a streak camera system (Hamamatsu C4780). A parabolic mirror was used to focus the excitation beam into the sample and the subsequent fluorescence was collected in a backscattering geometry using the same parabolic mirror. Magic angle detection was used to 

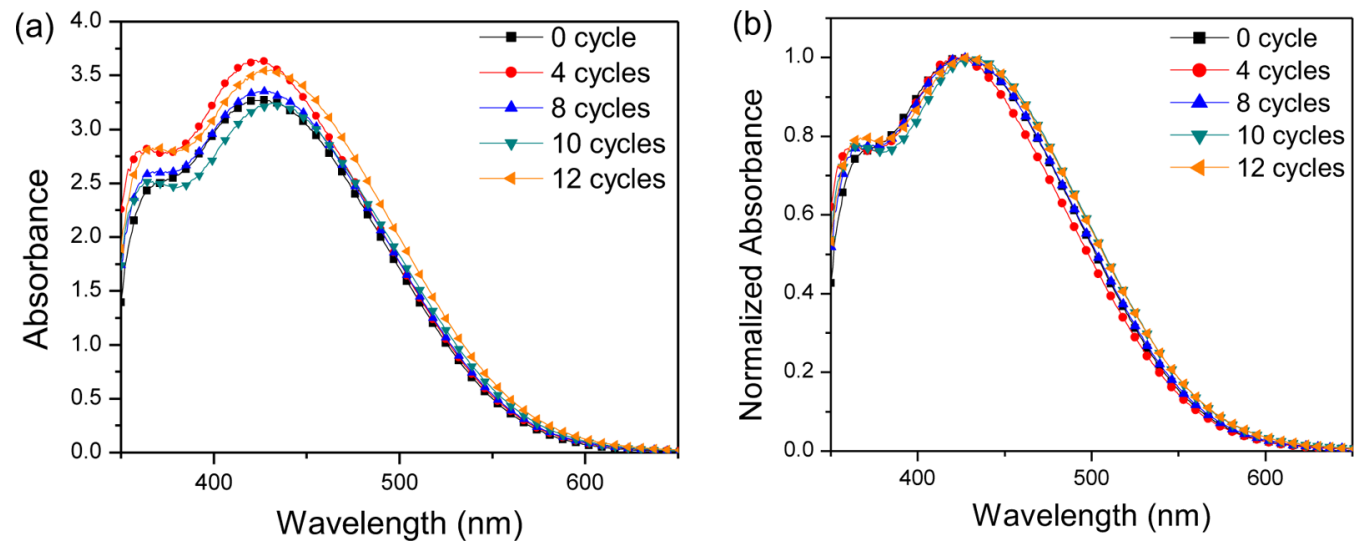

Figure 2. (a) Steady-state absorption spectra (in air) and (b) normalized spectra of $\mathrm{TiO}_{2}: \mathrm{OrgD}$ (in air) as a function of number $\mathrm{ALD} \mathrm{Al}_{2} \mathrm{O}_{3}$ process cycles.
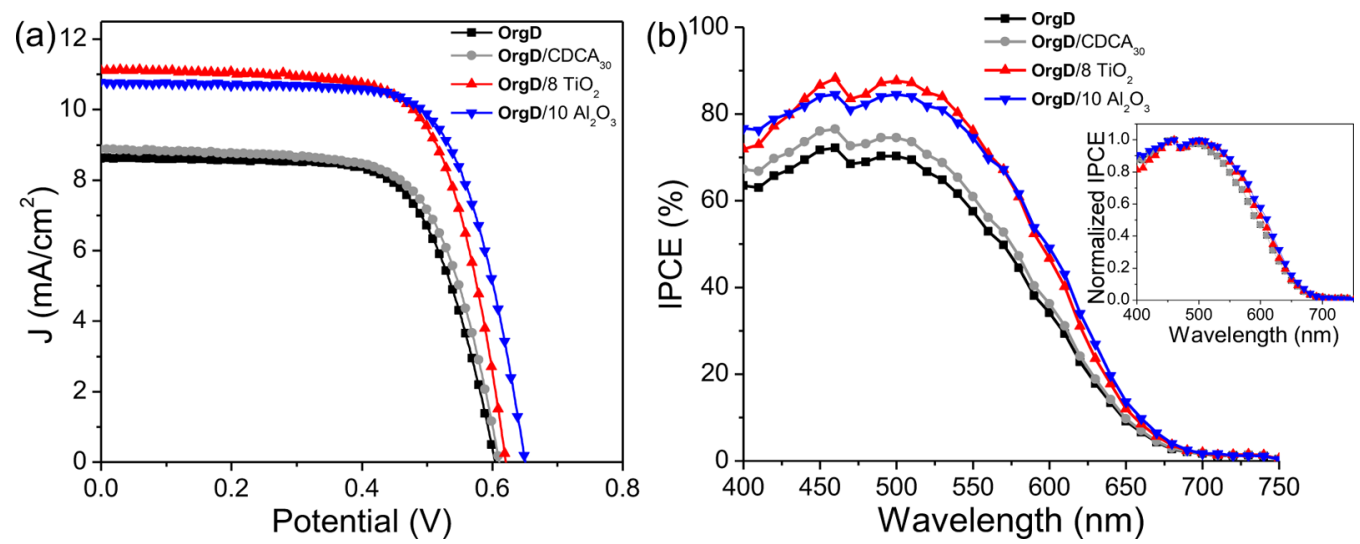

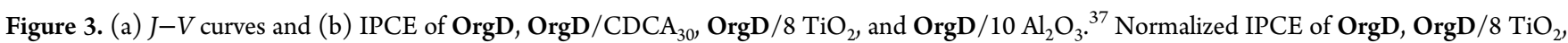
and $\operatorname{OrgD} / 10 \mathrm{Al}_{2} \mathrm{O}_{3}$ (inset, right).

avoid polarization effects. The IRF was $20 \mathrm{ps}(\mathrm{fwhm})$ in a $1 \mathrm{~ns}$ time window. All data were acquired in single photon counting mode using the Hamamatsu HPD-TA software.

\section{RESULTS AND DISCUSSION}

“Post-ALD" Treatment. We have previously shown that under the conditions used here $\mathrm{TiO}_{2}$ grows at a rate of $\sim 1 \AA$ per complete ALD cycle. ${ }^{32}$ For comparison, we also prepared post-ALD coated samples with alumina $\left(\mathrm{TiO}_{2}: \mathrm{OrgD} / \mathrm{Al}_{2} \mathrm{O}_{3}\right)$; $\mathrm{Al}_{2} \mathrm{O}_{3}$ is an insulator and might be expected to behave as a tunneling barrier with respect to back electron-transfer (i.e., interception of injected electrons by triiodide). Under the conditions used here, $\mathrm{Al}_{2} \mathrm{O}_{3}$ grows at a rate of $\sim 1 \AA$ per complete ALD cycle. ${ }^{32}$ (Deposition rates of the ALD process were determined by ellipsometry measurements (Figure S1 in the Supporting Information).) The $\mathrm{TiO}_{2}: \mathrm{OrgD} / 10 \mathrm{TiO}_{2}(10$ cycles ALD for $\mathrm{TiO}_{2}$ ) and $\mathrm{TiO}_{2}: \operatorname{OrgD} / 55 \mathrm{Al}_{2} \mathrm{O}_{3}$ (55 cycles ALD for $\mathrm{Al}_{2} \mathrm{O}_{3}$ ) films were scraped from their substrates for HRTEM measurements, and the images are shown in Figure 1; post-ALD layers of uniform thickness can be clearly observed on the surface of $\mathrm{TiO}_{2}$ nanoparticles (NPs). Energy-dispersive $\mathrm{X}$-ray spectroscopy (EDS) mapping of a cross section of a $\mathrm{TiO}_{2}: \mathrm{OrgD} / 10 \mathrm{Al}_{2} \mathrm{O}_{3}$ film revealed uniform distributions of $\mathrm{Ti}$, $\mathrm{Al}$, and $\mathrm{O}$, consistent with conformal coating and with ALDprecursor permeation of the entire photoelectrode (see Figure S3 in the Supporting Information).

Figure 2 shows $\mathrm{TiO}_{2}: \mathrm{OrgD}$ absorption spectra as a function of number of post-ALD cycles of $\mathrm{Al}_{2} \mathrm{O}_{3}$, respectively. As noted previously (with $\mathrm{SiO}_{2}{ }^{24}$ and $\mathrm{TiO}_{2}{ }^{32}$ ) and consistent with the donor-acceptor design of $\mathrm{OrgD}$, encapsulation by an oxide coating leads to small red shifts in the absorption maximum. Notably, however, the spectrum shape is unchanged, with none of the spectra showing hints of structure that would point to the presence of a dye aggregate.

Evaluation in Solar Cells. With modified structures in hand, we examined the performance of the ALD-treated and ALD-free photoanodes in DSCs based on OrgD. For comparison, we also examined DSCs containing $\mathrm{TiO}_{2}: \mathrm{OrgD} /$ $\mathrm{CDCA}_{30}$ photoanodes (i.e., dye coadsorbed from a solution containing 30 equiv of chenodeoxycholic acid (CDCA), a frequently used aggregation inhibitor). The $\mathrm{TiO}_{2} / \mathrm{OrgD}$ cell gave a short circuit photocurrent density $\left(J_{\mathrm{sc}}\right)$ of $10.1 \mathrm{~mA} / \mathrm{cm}^{2}$, an open circuit voltage $\left(V_{\mathrm{oc}}\right)$ of $604 \mathrm{mV}$, a fill factor $(\mathrm{FF})$ of 0.69 , and overall light-to-electrical-energy conversion efficiency $(\eta=3.6 \%)$. The $\mathrm{OrgD} / \mathrm{CDCA}_{30}$ cell exhibited nearly identical performance $(\eta=3.7 \%)$ to that of the $\mathrm{TiO}_{2} / \mathrm{OrgD}$ cell; see Figure 3 and Table 1. In view of previous work, ${ }^{38-42}$ as well as ALD results discussed in the next section, it may well be that CDCA favorably influences certain processes involved in DSC operation but at the expense of diminished dye loading and light harvesting.

Under the same conditions, cells post-treated by ALD with titania ( 8 cycles) and alumina (10 cycles), respectively, yielded substantially better performance: $J_{\mathrm{sc}}$ values of 11.1 and $10.7 \mathrm{~mA}$ $\mathrm{cm}^{-2}, V_{\text {oc }}$ values of 620 and $650 \mathrm{mV}$, fill-factors of 0.69 and 0.70 , and overall efficiencies of 4.8 and $4.9 \%$; again see Figure 3 
Table 1. Photovoltaic Performance of the DSSCs

\begin{tabular}{|c|c|c|c|c|c|}
\hline dye & $\begin{array}{c}\text { amount }^{a} \\
{\left[10^{-8} \mathrm{~mol} / \mathrm{cm}^{2}\right]}\end{array}$ & $\begin{array}{c}J_{\mathrm{sc}} \\
{\left[\mathrm{mA} / \mathrm{cm}^{2}\right]}\end{array}$ & $\begin{array}{l}V_{\mathrm{oc}} \\
{[\mathrm{V}]}\end{array}$ & FF & $\begin{array}{c}\eta \\
{[\%]}\end{array}$ \\
\hline OrgD & $7.82(1)^{b}$ & 8.6 & 0.604 & 0.69 & 3.6 \\
\hline$\underset{\mathrm{CDCA}_{30}}{\operatorname{OrgD} /}$ & $5.37(0.69)^{b}$ & 8.9 & 0.610 & 0.68 & 3.7 \\
\hline $\operatorname{OrgD} / 8 \mathrm{TiO}_{2}$ & $7.95(1.01)^{b}$ & 11.1 & 0.620 & 0.69 & 4.8 \\
\hline $\begin{array}{c}\text { OrgD/10 } \\
\mathrm{Al}_{2} \mathrm{O}_{3}\end{array}$ & $7.76(0.99)^{b}$ & 10.7 & 0.650 & 0.70 & 4.9 \\
\hline
\end{tabular}

${ }^{a}$ Obtained via dye desorption in basic ethanol and subsequent measurement of dye solution absorbance. ${ }^{b}$ Numbers in parentheses are amounts relative to $\operatorname{OrgD}$ (alone) on $\mathrm{TiO}_{2}$.

and Table 1. (Figure S4 and Table S1 in the Supporting Information contain data for DSCs modified different numbers of ALD cycles; qualitatively similar results were obtained.) Notably, and in contrast to most previous DSC-related implementations of ALD for multilayer insulator growth, ${ }^{43-51}$ the inclusion here of $\sim 10 \AA$ of alumina in the photoelectrode assembly yields significant improvements in power conversion efficiency without attenuating the electron injection. The main distinction between older and newer experiments is that in the former, ALD insulating layers were positioned between the dye and the semiconductor as an electron-tunneling type barrier layer. While the intent was to slow back electron transfer $(\mathrm{ET}){ }^{52}$ forward ET (dye injection) was also unavoidably slowed, ultimately resulting in diminished electron-injection yields, $\eta_{\text {inj }}$.

By introducing alumina instead as a dye-encapsulating layer, it is conceivable that back ET (either to the oxidized dye or to the oxidized shuttle, tri-iodide) could be slowed even if forward ET (dye injection) is not. In turn, this might explain the $~ 30 \%$ overall boost in energy-conversion efficiency. Experimental observables would include (a) increased $V_{\text {oc }}$ due to decreased dark current, (b) increased charge-collection length, $L_{\mathrm{n}}$, and (c) selective red enhancement of IPCE line shape. From Figure 4 and Table 1, alumina ALD (but not titania) indeed does slightly increase $V_{\mathrm{oc}}$. To determine how the electron-collection length may be affected, we recorded open-circuit voltage decay curves and dark electrochemical impedance spectra. The former yield potential-dependent survival times, $\tau_{\mathrm{e}}$, for injected electrons. The latter provide cell resistance data (see below) as well as potential-dependent electron-transport times, $\tau_{\mathrm{n}}$. These times are closely related to effective diffusion coefficients for electrons within the nanoparticulate photoelectrode. Estimates of the effective charge-collection length are available from

$$
L_{\mathrm{n}}=L\left(\tau_{\mathrm{e}} / \tau_{\mathrm{n}}\right)^{1 / 2}=L\left(R_{\mathrm{ct}} / R_{\mathrm{t}}\right)^{1 / 2}
$$

EIS results were fitted with the "Bisquert 2 model" equivalent circuit; $^{53}$ see the Supporting Information for further details. Charge-collection lengths of the modified electrodes and bare electrode were calculated based on the following equation, $L_{\mathrm{n}}=$ $L \times\left(R_{\mathrm{ct}} / R_{\mathrm{t}}\right)^{1 / 2}$, where $L_{\mathrm{n}}$ is the charge collection length, $L$ is the physical thickness of the photoanode film, $R_{c t}$ is the recombination resistance (the DSC equivalent-circuit resistance associated with back ET), and $R_{\mathrm{t}}$ is the diffusion resistance (the equivalent-circuit resistance associated with electron transport through the semiconductor). Thus, small electron-transport times or, equivalently, small electron-transport resistances permit electron collection over greater distances, i.e., greater electrode thicknesses. Large electron-survival times or, equivalently, large charge-resistances permit electron collection over greater distances, i.e., greater electrode thicknesses.

Our expectation was that post-ALD treatment would engender little change in $\tau_{\mathrm{n}}$ (or equivalently $R_{\mathrm{t}}$ ) and, indeed, this proved to be the case. Open-circuit voltage decay measurements, Figure $4 \mathrm{a}$, showed that post-ALD treatment with $\mathrm{TiO}_{2}$ causes a small, but observable, increase in electron survival time. Similar measurements with $\mathrm{Al}_{2} \mathrm{O}_{3}$ reveal slightly greater increases, e.g., a factor of 5 at $V_{\mathrm{oc}}=500 \mathrm{mV}$ for eight ALD cycles. The larger effects for alumina than titania are consistent with the insulating character of the former. Nevertheless, the effects are much less than observed with pure, dye-free alumina blocking layers. ${ }^{52}$ EIS measurements of $R_{\mathrm{ct}}$ corroborate the observed modest changes in values for $\tau_{\mathrm{e}}$; see the Supporting Information.

The available voltage-decay and EIS data yielded effective charge-collection lengths of $13-15 \mu \mathrm{m}$ for both $\mathrm{TiO}_{2}$ and $\mathrm{Al}_{2} \mathrm{O}_{3}$ treated cells, slightly longer than that of the nontreated cell $(\sim 11 \mu \mathrm{m})$. EIS also revealed that the untreated and treated cells have a similar capacitance, indicating that the conductionband-edge energy of the nanoporous $\mathrm{TiO}_{2}$ network is not appreciably affected by the ALD post-treatment ${ }^{54}$ (see Figure S6 in the Supporting Information). In our experience, chargecollection lengths derived from dark measurements (the case here) tend to exceed the actual charge-collection lengths
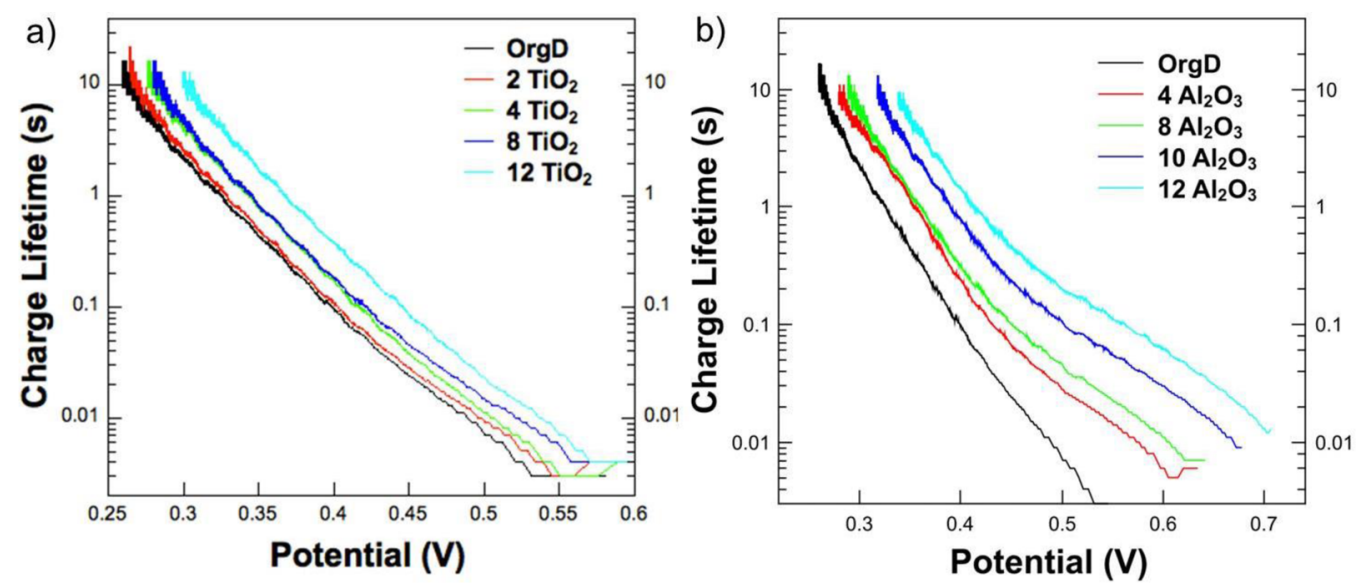

Figure 4. Charge lifetimes from open-circuit photovoltage decay measurements of DSCs with increasing numbers of cycles of (a) $\mathrm{TiO}_{2}$ and (b) $\mathrm{Al}_{2} \mathrm{O}_{3}$ post $\mathrm{ALD}$ deposition. 
displayed by operating cells under illumination. ${ }^{55}$ Nevertheless, the dark measurements seem to capture well the relative changes in $L_{\mathrm{n}}$. From these, we conclude that slightly more photocurrent should be observed with post-ALD treated cells, especially on the red-edge of the light-harvesting spectrum where significant light penetration can occur even at the back edge of the photoelectrode. Little photocurrent enhancement due to improved charge collection should occur, however, for illumination at the dye absorption maximum $(\sim 430 \mathrm{~nm})$ where light infiltration distances are shortest. To test these notions, we compared normalized IPCE plots. As shown in Figure $3 \mathrm{~b}$ (inset), the plots have nearly identical shapes, albeit with slightly greater long-wavelength contributions from post-ALD treated cells. From the close agreement, we conclude that improved charge collection (i.e., inhibition of electron interception by the redox shuttle) can account for no more than $2 \%$ percent of the $\sim 30 \%$ overall improvement in energy conversion efficiency brought about by ALD post-treatment.

An attractive alternative explanation is that post-treatment eliminates residual aggregation of the sensitizing dye and that this, in turn, boosts the yield for electron injection by the photoexcited dye. In part, because of shortened excited-state lifetimes, aggregated dye molecules typically do not inject as efficiently as nonaggregated dyes. ${ }^{56-58}$ The overall injection yield could be low if injection occurs mainly through very shortlived aggregate excited states where "very short" means comparable to injection time. Absorption spectra (e.g., Figure 2) provide little evidence for aggregation. Nevertheless, even a tiny amount of aggregated dye could, in principle, exert a large effect if monomeric dyes engaged in energy transfer to the aggregate rather than in direct injection. As detailed below, transient optical measurements provide a means of detecting minority aggregate species.

The overall photocurrent efficiency is the product of the LHE (essentially unchanged; Figure 1), the charge-collection efficiency (a $2 \%$ improvement or less; see inset for Figure 3), and the injection yield. On this basis, the relative improvement in injection yield due to $\mathrm{TiO}_{2}$ post ALD treatment is estimated to be $25 \%$. The photocurrent action spectra (IPCE plots) display flattened features relative to absorption spectra, as expected for photelectrodes that feature both good charge collection efficiencies and high optically densities across much of the spectrum. The maximum observed IPCE value is $85 \%$. Given that cumulative reflection and scattering losses are difficult to reduce below $15 \%$ with DSCs containing the materials used here, the injection yield for $\mathrm{TiO}_{2}$ post-ALD treated electrodes is nearly quantitative, while the injection yield for untreated photoelectrodes is estimated to be $\sim 80 \%$.

Optical Spectroscopy. To cement our understanding of how ALD post-treatment enhances cell efficiency, steady-state, and time-resolved fluorescence (TRF) measurements for four $\mathrm{TiO}_{2}$ :OrgD samples on a glass (BK7) window were performed. We were interested, in particular, how the dynamics of interfacial electron injection from the photoexcited dye was affected by ALD post-treatment. Thus, we examined the following photoelectrode assemblies: (1) $\mathrm{TiO}_{2}: \operatorname{OrgD}$, (2) $\mathrm{TiO}_{2}:$ OrgD/CDCA 30 (CDCA, 30 equiv), (3) $\mathrm{TiO}_{2}:$ OrgD $/ 8$ $\mathrm{TiO}_{2}$ (8 cycles ALD for $\mathrm{TiO}_{2}$ ), and (4) $\mathrm{TiO}_{2}: \mathrm{OrgD} / 10 \mathrm{Al}_{2} \mathrm{O}_{3}$ (10 cycles ALD for $\mathrm{Al}_{2} \mathrm{O}_{3}$ ). Additionally, quartz-supported, solid films of either $\operatorname{OrgD}_{\text {agg }}$ (only $\operatorname{OrgD}$ ) or $\operatorname{OrgD}_{\text {free }}$ (with a large excess of CDCA, >1000 equiv) were prepared (using drop-casting). These $\mathrm{TiO}_{2}$-free films were used as noninjecting reference points for the behavior of aggregated and nonaggregated forms of the dyes, respectively.

The absorption spectra of the reference samples, the $\operatorname{OrgD}_{\mathrm{agg}}$ and $\mathrm{OrgD}_{\text {free }}$, show a large difference in spectral shape (Figure $5 a)$. The absorption band of the $\operatorname{OrgD}_{\text {agg }}$ is red-shifted to 500
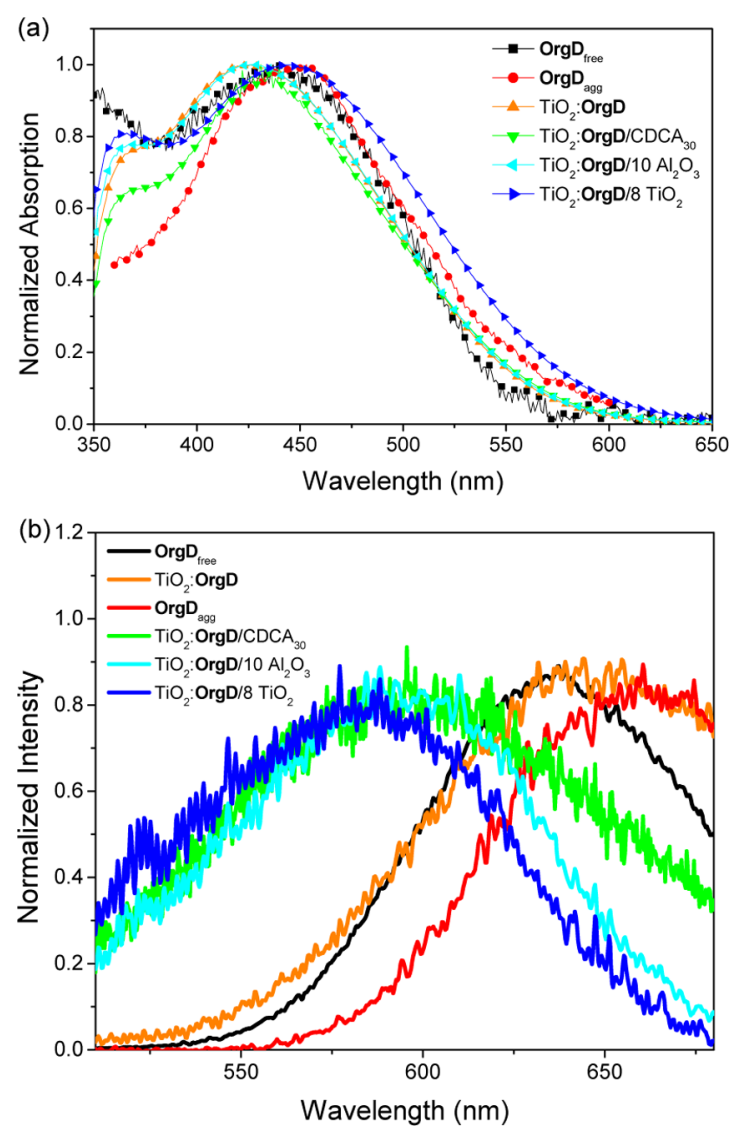

Figure 5. (a) Steady state absorption and (b) fluorescence spectra of the solid film samples.

$\mathrm{nm}$, and a shoulder around $570 \mathrm{~nm}$ is larger relative to that of the $\operatorname{OrgD} D_{\text {free }}$. Such behavior is reminiscent of aggregationinduced red-shifts reported in a different dye system. ${ }^{38}$ Two possible explanations for the red-shifted band are (1) J-type aggregation, and (2) aggregation-induced planarization. ${ }^{59}$ Semiempirical calculations of the absorption bands for the twisted and planar geometries (see Figure S8 in the Supporting Information) support the latter case, where the absorption maximum of the twisted form is located at $400 \mathrm{~nm}$. Indeed, the absorption spectrum of $\operatorname{OrgD}_{\text {agg }}$ shows a relatively low absorbance around $400 \mathrm{~nm}$, indicating planarization of molecular geometry on the substrate.

Steady-state and time-resolved fluorescence spectra gave a wealth of information about the samples. Two reference samples, $\operatorname{Org} D_{\text {agg }}$ and $\operatorname{OrgD}_{\text {free }}$ show emission bands around $650 \mathrm{~nm}$ that are red-shifted relative to the emission spectrum of the $\mathrm{TiO}_{2}: \operatorname{OrgD} / \mathrm{CDCA}_{30}$ and ALD post-treated samples (Figure 5). However, it is reasonable to assume that intermolecular interaction dynamics in the excited state is negligible for $\operatorname{OrgD}_{\text {free. }}$. The origin of the dynamic red shift of the fluorescence emission from $\operatorname{OrgD}_{\text {free }}$ should result from intramolecular relaxation dynamics after photoexcitation. In $\operatorname{OrgD}_{\text {free, }}$ no ultrafast decay component shorter than 20 ps is observed, but only relatively slow dynamic Stokes shifts were 
resolved (Figures S9a,b and S10a in the Supporting Information). The center wavelength of the TRF spectrum of $\operatorname{OrgD}_{\text {free }}$ at time zero is $580 \mathrm{~nm}$, but its spectrum is red-shifted to $640 \mathrm{~nm}$ at $700 \mathrm{ps}$. A first moment analysis of the TRF spectra gave two time constants of 25 and 250 ps (Figure S10b in the Supporting Information). Both intramolecular vibronic relaxation ${ }^{60}$ and structural dynamics ${ }^{61}$ have been invoked to explain the relatively slow dynamic Stokes shifts. On the other hand, the $\operatorname{OrgD}_{\mathrm{agg}}$ shows different relaxation dynamics. The center wavelength of the $\mathbf{O r g D}_{\text {agg }}$ TRF spectrum was about 640 $\mathrm{nm}$ and its dynamic Stokes shift was negligible. The first decay component was ultrafast ( $<5 \mathrm{ps})$ and dominant, indicating that there is an ultrafast quenching process even in the aggregated state. Although picosecond TRF spectra of the other solar cell samples with $\mathrm{TiO}_{2}$ also showed similar ultrafast quenching dynamics (see Table S4 in the Supporting Information), the origin of the ultrafast quenching in the aggregated dye should be distinguished from the interfacial electron injection dynamics. Therefore, each of the 580 (at time zero) and 660 $\mathrm{nm}$ emission bands can be assigned to the isolated and aggregated states of the dyes, respectively.

Two samples treated with post $\mathrm{ALD}, \mathrm{TiO}_{2}: \mathrm{OrgD} / 8 \mathrm{TiO}_{2}$ and $\mathrm{TiO}_{2}: \mathrm{OrgD} / 10 \quad \mathrm{Al}_{2} \mathrm{O}_{3}$ show blue-shifted steady state fluorescence spectra $\left(\lambda_{\max }=580 \mathrm{~nm}\right)$ relative to that of reference samples (Figure $5 \mathrm{~b}$ ). In particular, the band at 680 $\mathrm{nm}$ assigned to the aggregated state of the dyes is negligible. These results indicate that the ALD post-treatments efficiently suppress dye aggregation. Note that the negligible Stokes shifts of the emission bands in the ALD post-treated samples are due to the fact that the ultrafast electron injection dynamics are faster than the dynamic Stokes shifts (vide infra).

Interestingly, the shapes of the emission spectra of $\mathrm{TiO}_{2}:$ OrgD and $\mathrm{TiO}_{2}:$ OrgD/CDCA 30 are similar to a sum of those of the two reference samples (the emission spectra of $\operatorname{OrgD} D_{\text {free }}$ at time zero and the steady-state emission spectrum of $\left.\operatorname{OrgD}_{\mathrm{agg}}\right)$, and we can reasonably separate the contribution from dye aggregation in $\mathrm{TiO}_{2}: \mathrm{OrgD}$ and $\mathrm{TiO}_{2}: \operatorname{OrgD} / \mathrm{CDCA}_{30}$ by subtracting the fluorescence spectrum of $\operatorname{OrgD}_{\text {agg. }}$. From the deconvoluted spectra of the $\mathrm{TiO}_{2}$ :OrgD film based on the picosecond TRF results (Figure 6a), we conclude that a sizable fraction of the light emitted at short times is aggregated dye. At the same time, however, ground state absorption spectra (Figure 2) indicate little aggregation. The disparity can be rationalized if (a) nonaggregated dye molecules are sensitizing, via energy transfer, emission from aggregated ones, and/or (b) we recognize that electron injection into $\mathrm{TiO}_{2}$ by nonaggregated dye molecules is much faster than by aggregated molecules, resulting in disproportionate quenching of emission by the nonaggregated dye. Regardless, in this study, the ultrafast emission spectrum is a much more sensitive reporter on dye aggregation than is ground-state electronic absorption. This point is further illustrated in Figure $6 \mathrm{~b}$; the dominant emission band at $580 \mathrm{~nm}$ for $\mathrm{TiO}_{2}$ :OrgD/CDCA 30 demonstrates that CDCA indeed suppresses dye aggregation, but there still exists a $660 \mathrm{~nm}$ emission band (indicative of the presence of dye aggregates). Thus, the common antiaggregation agent, CDCA, does not fully prevent dye aggregation. This finding is consistent with the notion that photocurrent production by $\mathrm{TiO}_{2}:$ OrgD/CDCA 30 is limited, in part, by the yield for electron-injection, whereas photocurrent production by postALD treated electrodes is not.

Via the deconvoluted steady-state fluorescence spectra, it is possible to selectively monitor the dynamics of two ultrafast
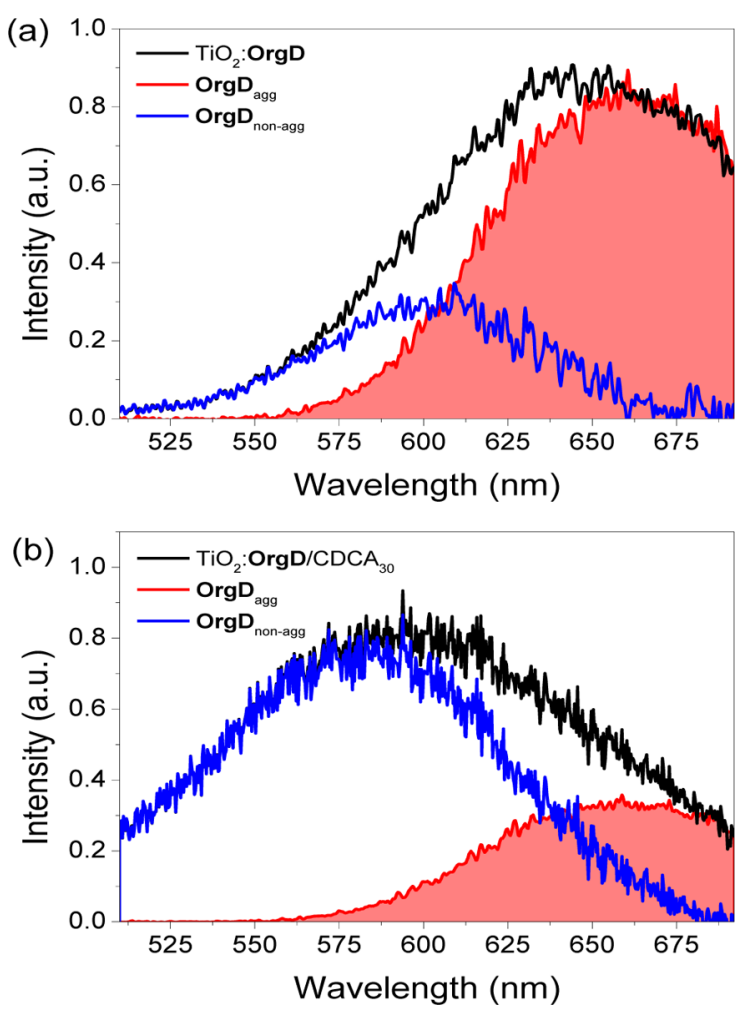

Figure 6. Deconvoluted steady-state fluorescence spectra of the $\mathrm{TiO}_{2}: \operatorname{OrgD}(\mathrm{a})$ and the $\mathrm{TiO}_{2}: \operatorname{OrgD} / \mathrm{CDCA}_{30}(\mathrm{~b})$. The steady-state fluorescence spectrum of the $\operatorname{OrgD}_{\mathrm{agg}}$ was used to retrieve the contribution of the nonaggregated $\operatorname{OrgD}\left(\operatorname{OrgD} D_{\text {nonagg }}\right)$ on the $\mathrm{TiO}_{2}$ film. Note that the reconstructed spectrum of the $\mathbf{O r g D}_{\text {nonagg }}$ is close to the fluorescence spectrum of $\mathbf{O r g D}_{\text {free }}$ at time zero.

quenching processes by femtosecond TRF at two detection wavelengths: $580 \mathrm{~nm}$ for the interfacial electron injection dynamics between the $\mathrm{TiO}_{2}$ nanoparticles and $\mathrm{OrgD}$ and 680 $\mathrm{nm}$ (chosen to avoid overlap with the $\operatorname{OrgD}_{\text {nonagg }}$ emission band) for the ultrafast quenching dynamics occurring in the aggregated state.

Figure 7 shows femtosecond TRF results on the solid film samples. The multiexponential fits are summarized in Table 2. In the case of $\operatorname{OrgD}_{\mathrm{agg}}$, we view the first decay components of $340 \pm 40$ and $394 \pm 77 \mathrm{fs}$ measured at both 580 and $680 \mathrm{~nm}$ as arising from ultrafast quenching dynamics in the aggregated state because the same component is observed at $680 \mathrm{~nm}$, i.e., there is no dependence on detection wavelength. Small discrepancies in decay times and amplitudes may be due to an ultrafast vibronic relaxation. The ultrafast quenching rate in the aggregated state is thought to arise from energy transfer between dyes or from internal conversion via strong vibronic coupling between the $S_{0}$ and $S_{1}$ states. At the $580 \mathrm{~nm}$ detection wavelength, the ultrafast interfacial electron injection time of about 150-190 fs was resolved for all $\mathrm{TiO}_{2}$ :OrgD samples.

An ultrafast decay component followed by two slower picosecond decay components was observed in all samples except $\operatorname{OrgD}_{\text {agg }}$. At the $680 \mathrm{~nm}$ detection wavelength, as a result of the contribution from the aggregated form, $\mathrm{TiO}_{2}$ :OrgD and $\mathrm{TiO}_{2}:$ OrgD/CDCA 30 reveal fast decay times of $345 \pm 39$ and $333 \pm 32$ fs, respectively. Notably, these values are similar to those of the OrgD $_{\text {agg. }}$ This result indicates that the aggregated dyes on $\mathrm{TiO}_{2}$ nanoparticles do not contribute to the desired electron injection due to the competing aggregation quenching. In contrast, the two ALD treated samples, $\mathrm{TiO}_{2}: \mathrm{OrgD} / 8 \mathrm{TiO}_{2}$ 

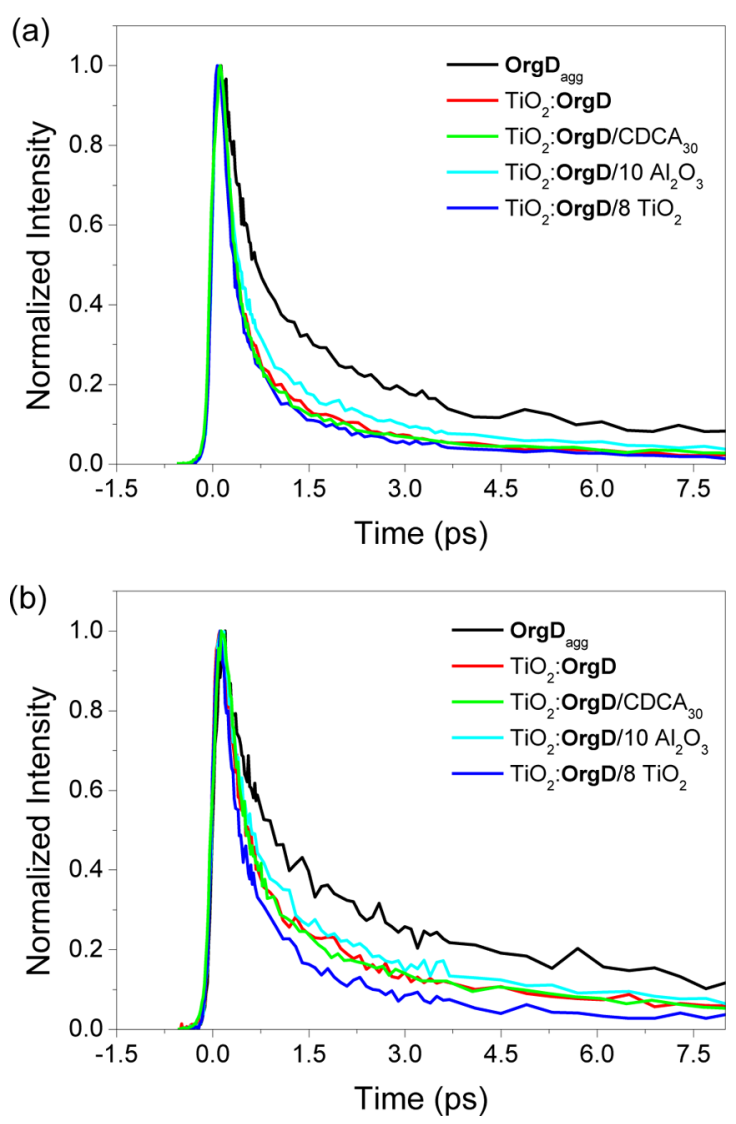

Figure 7. Femtosecond time-resolved fluorescence kinetics monitored at $580 \mathrm{~nm}$ (a) and $680 \mathrm{~nm}$ (b).

and $\mathrm{TiO}_{2}: \mathrm{OrgD} / 10 \mathrm{Al}_{2} \mathrm{O}_{3}$, show fast decay times of $163 \pm 31$ and $277 \pm 57 \mathrm{fs}$, respectively. Note that these values are rather close to fast decay times of $148 \pm 15$ and $190 \pm 29$ fs measured at $580 \mathrm{~nm}$ and second decay times $\left(\tau_{2}\right)$ also showed a similar behavior, indicating a negligible contribution from the aggregated form. In turn, the observations demonstrate that the post ALD treatment isolates dye molecules, enabling the overwhelming majority of them to participate in the desired direct electron-injection process. ${ }^{62,63}$

Interestingly, the interfacial electron transfer rate with $\mathrm{TiO}_{2}:$ OrgD/8 $\quad \mathrm{TiO}_{2}$ was slightly faster than that with $\mathrm{TiO}_{2}:$ OrgD/10 $\mathrm{Al}_{2} \mathrm{O}_{3}$. Second decay components $\left(\tau_{2}\right)$ likewise indicated faster electron transfer for $\mathrm{TiO}_{2}$-enshrouded $\mathrm{OrgD}$ than for the alumina-enshrouded version. One possibility is that electrode/dye electronic coupling is boosted in the $\mathrm{TiO}_{2}$ case. ${ }^{26}$
ALD-engendered enshrouding provides additional points of contact between the dye and semiconductor, albeit nonbonding contacts. Overall photophysical reaction pathways of the $\mathrm{TiO}_{2}$ :OrgD DSCs are summarized in Figure 8.

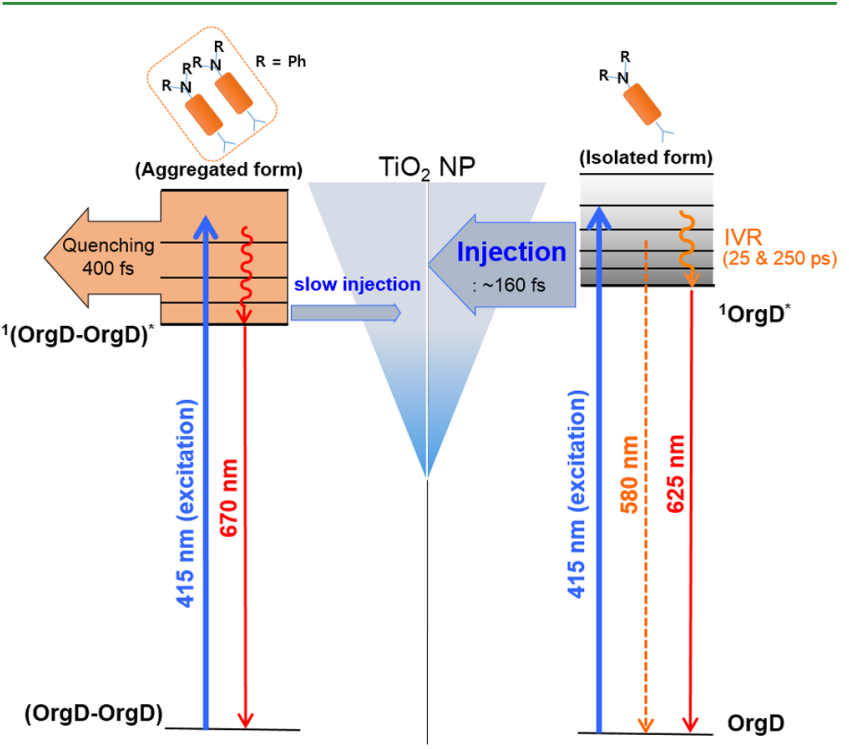

Figure 8. Energetics and interfacial processes occurring in the aggregated and isolated forms of OrgD within DSSCs. The $\mathrm{TiO}_{2}$ acceptor states are shown as an exponential distribution.

\section{CONCLUSIONS}

ALD post-treatment processing of a representative organic sensitizer adsorbed on a $\mathrm{TiO}_{2}$ photoelectrode is effective in disrupting deleterious intermolecular (i.e., adsorbed-dye/ adsorbed-dye) interactions and enhancing overall energyconversion efficiencies. For the system examined, this approach to blocking or reversing dye aggregation is superior to using the popular aggregation-inhibiting coadsorbent, CDCA. The very short excited-state lifetime of the aggregated form of the dye results in a diminished yield for electron injection. By breaking up residual aggregates, the ALD post-treatment enhances the injection yield and, therefore, the DSC photocurrent and overall energy-conversion efficiency. In contrast to conventional ALD pretreatment (i.e., ALD prior to dye loading), the post treatment does not interfere with dye/semiconductor electronic coupling and, therefore, does not slow injection kinetics.

Table 2. Multi-Exponential Fitting Results of Femtosecond Time-Resolved Fluorescence Signals ${ }^{a}$

\begin{tabular}{|c|c|c|c|c|c|c|c|}
\hline$(\mathrm{nm})$ & sample & $A_{1}(\%)$ & $\tau_{1}(\mathrm{fs})$ & $A_{2}(\%)$ & $\tau_{2}(\mathrm{ps})$ & $A_{3}(\%)$ & $\tau_{3}(\mathrm{ps})$ \\
\hline \multirow[t]{5}{*}{580} & OrgD $_{\text {agg }}$ & 60.4 & $340(40)$ & 34.4 & $2.18(0.47)$ & 5.2 & $>8$ \\
\hline & $\mathrm{TiO}_{2}:$ OrgD & 72.2 & $168(16)$ & 21.7 & $0.85(0.35)$ & 6.2 & $>8$ \\
\hline & $\mathrm{TiO}_{2}: \operatorname{OrgD} / \mathrm{CDCA}_{30}$ & 79.1 & $184(18)$ & 17.3 & $1.01(0.54)$ & 3.6 & $>8$ \\
\hline & $\mathrm{TiO}_{2}: \operatorname{OrgD} / 10 \mathrm{Al}_{2} \mathrm{O}_{3}$ & 66.8 & $190(29)$ & 24.8 & $0.93(0.39)$ & 8.4 & $5.9(2.7)$ \\
\hline & $\mathrm{TiO}_{2}: \operatorname{OrgD} / 8 \mathrm{TiO}_{2}$ & 69.3 & $148(15)$ & 24.8 & $0.65(0.19)$ & 6.0 & $4.5(1.9)$ \\
\hline \multirow[t]{5}{*}{680} & OrgD $_{\text {agg }}$ & 52.3 & $394(77)$ & 39.0 & $2.7(0.90)$ & 8.7 & $>8$ \\
\hline & $\mathrm{TiO}_{2}:$ OrgD & 72.8 & $345(39)$ & 23.9 & $2.5(1.00)$ & 3.3 & $>8$ \\
\hline & $\mathrm{TiO}_{2}: \operatorname{OrgD} / \mathrm{CDCA}_{30}$ & 77.1 & $333(32)$ & 19.8 & $2.7(1.01)$ & 3.1 & $>8$ \\
\hline & $\mathrm{TiO}_{2}:$ OrgD/10 Al $2 \mathrm{O}_{3}$ & 59.2 & $277(57)$ & 25.2 & $1.1(0.43)$ & 15.6 & $>8$ \\
\hline & $\mathrm{TiO}_{2}: \operatorname{OrgD} / 8 \mathrm{TiO}_{2}$ & 58.3 & $163(31)$ & 32.5 & $0.72(0.28)$ & 9.2 & $>8$ \\
\hline
\end{tabular}

${ }^{a}$ The numbers in parentheses are fitting errors. 
We speculate that, in the absence of the ALD post treatment, energy from monomeric dye excited-states can be transferred to residual aggregated dye species whose concentration is too low to be easily observed by ground-state electronic absorption. Thus, even a small degree of aggregation could, in principle, exert an outsized influence. A minor additional contributor to the $\sim 30 \%$ overall improvement in DSC efficiency is a modest decrease in the rate of interception of injected electrons by triiodide, the oxidized form of the redox shuttle. The rate decrease serves to increase slightly the photoelectrode's chargecollection length, thereby increasing by a few percent contributions to the short-current density from long wavelength irradiation. By suppressing dark current, the rate decrease also serves to increase slightly (i.e., by a few tens of millivolts) the open-circuit photovoltage.

\section{ASSOCIATED CONTENT}

\section{S Supporting Information}

Ellipsometry data of $\mathrm{TiO}_{2}$ and $\mathrm{Al}_{2} \mathrm{O}_{3}$ ALD layer on Si substrate; SEM and EDS image of $\mathrm{TiO}_{2}: \mathrm{OrgD} / 10 \mathrm{Al}_{2} \mathrm{O}_{3}$ film; photophysical, photovoltaic performance, EIS, and chemical capacitance data of $\mathrm{TiO}_{2}: \operatorname{OrgD}, \mathrm{TiO}_{2}: \operatorname{OrgD} / 8 \mathrm{TiO}_{2}$, and $\mathrm{TiO}_{2}: \mathrm{OrgD} / 10 \quad \mathrm{Al}_{2} \mathrm{O}_{3}$ cells. This material is available free of charge via the Internet at http://pubs.acs.org.

\section{AUTHOR INFORMATION}

\section{Corresponding Authors}

*E-mail: hjson@korea.ac.kr.

*E-mail: j-hupp@northwestern.edu.

\section{Present Addresses}

${ }^{\perp}$ C.H.K.: Pohang Accelerator Laboratory, POSTECH, Pohang 790-784, Korea.

${ }^{+}$C.P.: Department of Chemistry, Kasetsart University, Bangkok 10900, Thailand.

\section{Author Contributions}

${ }^{\otimes}$ H.-J.S. and C.H.K. contributed equally.

\section{Notes}

The authors declare no competing financial interest.

\section{ACKNOWLEDGMENTS}

J.T.H. and O.K.F. gratefully acknowledge support from the U.S. Department of Energy, Office of Science, Basic Energy Sciences (Grant No. DE-FG02-87ER13808) and Northwestern University, respectively. M.R.W. gratefully acknowledges support by the Chemical Sciences, Geosciences, and Biosciences Division, Office of Basic Energy Sciences, DOE under Grant No. DE-FG02-99ER14999.

\section{ABBREVIATIONS}

OrgD, organic dye ((E)-2-cyano-3-(5'-(5')-(p(diphenylamino)phenyl)-thiophen-2 ${ }^{\prime \prime}$-yl)thiophen- $2^{\prime}$-yl)acrylic acid)

post-ALD, postatomic layer deposition

CDCA, chenodeoxycholic acid

\section{REFERENCES}

(1) O’Regan, B.; Grätzel, M. A Low-Cost, High-Efficiency Solar Cell Based on Dye-Sensitized Colloidal $\mathrm{TiO}_{2}$ Films. Nature 1991, 353, 737-740.

(2) Grätzel, M. Photoelectrochemical Cells. Nature 2001, 414, 338344.
(3) Wang, P.; Klein, C.; Humphry-Baker, R.; Zakeeruddin, S. M.; Grätzel, M. A High Molar Extinction Coefficient Sensitizer for Stable Dye-Sensitized Solar Cells. J. Am. Chem. Soc. 2005, 127, 808-809.

(4) Robertson, N. Optimizing Dyes for Dye-Sensitized Solar Cells. Angew. Chem., Int. Ed. 2006, 45, 2338-2345.

(5) Hagfeldt, A.; Boschloo, G.; Sun, L.; Kloo, L.; Pettersson, H. DyeSensitized Solar Cells. Chem. Rev. 2010, 110, 6595-6663.

(6) Mishra, A.; Fischer, M. K. R.; Bäuerle, P. Metal-Free Organic Dyes for Dye-Sensitized Solar Cells: From Structure: Property Relationships to Design Rules. Angew. Chem., Int. Ed. 2009, 48, 2474-2499.

(7) Zeng, W. D.; Cao, Y. M.; Bai, Y.; Wang, Y. H.; Shi, Y. S.; Zhang, M.; Wang, F. F.; Pan, C. Y.; Wang, P. Efficient Dye-Sensitized Solar Cells with an Organic Photosensitizer Featuring Orderly Conjugated Ethylenedioxythiophene and Dithienosilole Blocks. Chem. Mater. 2010, 22, 1915-1925.

(8) Bessho, T.; Zakeeruddin, S. M.; Yeh, C.-Y.; Diau, E. W.-G.; Grätzel, M. Highly Efficient Mesoscopic Dye-Sensitized Solar Cells Based on Donor-Acceptor-Substituted Porphyrins. Angew. Chem., Int. Ed. 2010, 49, 6646-6649.

(9) Choi, H.; Raabe, I.; Kim, D.; Teocoli, F.; Kim, C.; Song, K.; Yum, J.-H.; Ko, J.; Nazeeruddin, M.; Grätzel, M. High Molar Extinction Coefficient Organic Sensitizers for Efficient Dye-Sensitized Solar Cells. Chem.-Eur. J. 2010, 16, 1193-1201.

(10) Yella, A.; Lee, H.-W.; Tsao, H. N.; Yi, C.; Chandiran, A. K.; Nazeeruddin, M. K.; Diau, E. W.-G.; Yeh, C.-Y.; Zakeeruddin, S. M.; Grätzel, M. Porphyrin-Sensitized Solar Cells with Cobalt (II/III)Based Redox Electrolyte Exceed 12\% Efficiency. Science 2011, 334, 629-634.

(11) Koumura, N.; Wang, Z.-S.; Mori, S.; Miyashita, M.; Suzuki, E.; Hara, K. Alkyl-Functionalized Organic Dyes for Efficient Molecular Photovoltaics. J. Am. Chem. Soc. 2006, 128, 14256-14257.

(12) Choi, H.; Baik, C.; Kang, S. O.; Ko, J.; Kang, M.-S.; Nazeeruddin, M. K.; Grätzel, M. Highly Efficient and Thermally Stable Organic Sensitizers for Solvent-Free Dye-Sensitized Solar Cells. Angew. Chem., Int. Ed. 2008, 47, 327-330.

(13) Pechy, P.; Rotzinger, F. P.; Nazeeruddin, M. K.; Kohle, O.; Zakeeruddin, S. M.; Robin Humphry-Baker, R.; Grätzel, M. Preparation of Phosphonated Polypyridyl Ligands to Anchor Transition-Metal Complexes on Oxide Surfaces: Application for the Conversion of Light to Electricity with Nanocrystalline $\mathrm{TiO}_{2}$ Films. J. Chem. Soc. Chem. Commun. 1995, 65-66.

(14) Gillaizeau-Gauthier, I.; Odobel, F.; Alebbi, M.; Argazzi, R.; Costa, E.; Bignozzi, C. A.; Qu, P.; Meyer, G. J. Phosphonate-Based Bipyridine Dyes for Stable Photovoltaic Devices. Inorg. Chem. 2001, 40, 6073-6079.

(15) Yan, S. G.; Prieskorn, J. S.; Kim, Y.; Hupp, J. T. In Search of the Inverted Region:- Chromophore-Based Driving Force Dependence of Interfacial Electron Transfer Reactivity at the Nanocrystalline Titanium Dioxide Semiconductor/Solution Interface. J. Phys. Chem. B 2000, 104, 10871-10877.

(16) Trammell, S. A.; Moss, J. A.; Yang, J. C.; Nakhle, B. M.; Slate, C. A.; Odobel, F.; Sykora, M.; Erickson, B. W.; Meyer, T. J. Sensitization of $\mathrm{TiO}_{2}$ by Phosphonate-Derivatized Proline Assemblies. Inorg. Chem. 1999, 38, 3665-3669.

(17) Heimer, T. A.; D’Arcangelis, S. T.; Farzad, F.; Stipkala, J. M.; Meyer, G. J. An Acetylacetonate-Based Semiconductor-Sensitizer Linkage. Inorg. Chem. 1996, 35, 5319-5324.

(18) McNamara, W. R.; Snoeberger, R. C., III; Li, G.; Schleicher, J. M.; Cady, C. W.; Poyatos, M.; Schmuttenmaer, C. A.; Crabtree, R. H.; Brudvig, G. W.; Batista, V. S. Acetylacetonate Anchors for Robust Functionalization of $\mathrm{TiO}_{2}$ Nanoparticles with $\mathrm{Mn}(\mathrm{II})$-Terpyridine Complexes. J. Am. Chem. Soc. 2008, 130, 14329-14338.

(19) Sokolow, J. D.; Trzop, E.; Chen, Y.; Tang, J.; Allen, L. J.; Crabtree, R. H.; Benedict, J. B.; Coppens, P. Binding Modes of Carboxylate- and Acetylacetonate-Linked Chromophores to Homodisperse Polyoxotitanate Nanoclusters. J. Am. Chem. Soc. 2012, 134, 11695-11700. 
(20) McNamara, W. R.; Snoeberger, R. C., III; Li, G.; Richter, C.; Allen, L. J.; Milot, R. L.; Schmuttenmaer, C. A.; Crabtree, R. H.; Brudvig, G. W.; Batista, V. S. Hydroxamate Anchors for Water-Stable Attachment to $\mathrm{TiO}_{2}$ Nanoparticles. Energy Environ. Sci. 2009, 2, 11731175.

(21) Feldt, S. M.; Cappel, U. B.; Johansson, E. M. J.; Boschloo, G.; Hagfeldt, A. Characterization of Surface Passivation by Poly(methylsiloxane) for Dye-Sensitized Solar Cells Employing the Ferrocene Redox Couple. J. Phys. Chem. C 2010, 114, 10551-10558. (22) Park, S.-H.; J. Lim, J.; Song, I. Y.; Atmakuri, N.; Song, S.; Kwon, Y. S.; Choi, J. M.; Park, T. Stable Dye-Sensitized Solar Cells by Encapsulation of N719-Sensitized $\mathrm{TiO}_{2}$ Electrodes Using SurfaceInduced Cross-Linking Polymerization. Adv. Energy Mater. 2012, 2, 219-224.

(23) Wee, K.-R.; Brennaman, M. K.; Alibabaei, L.; Farnum, B. H.; Sherman, B.; Lapides, A. M.; Meyer, T. J. Stabilization of Ruthenium(II) Polypyridyl Chromophores on Nanoparticle MetalOxide Electrodes in Water by Hydrophobic PMMA Overlayers. J. Am. Chem. Soc. 2014, 136, 13514-13517.

(24) Son, H.-J.; Wang, X.; Prasittichai, C.; Jeong, N. C.; Aaltonen, T.; Gordon, R. G.; Hupp, J. T. Glass-Encapsulated Light Harvesters: More Efficient Dye-Sensitized Solar Cells by Deposition of Self-Aligned, Conformal, and Self-Limited Silica Layers. J. Am. Chem. Soc. 2012, 134, 9537-9540.

(25) Kim, D. H.; Losego, M. D.; Hanson, K.; Alibabaei, L.; Lee, K.; Meyer, T. J.; Parsons, G. N. Stabilizing Chromophore Binding on $\mathrm{TiO}_{2}$ for Long-Term Stability of Dye-Sensitized Solar Cells Using Multicomponent Atomic Layer Deposition. Phys. Chem. Phys. Chem. 2014, 16, 8615-8622.

(26) Hanson, K.; Losego, M. D.; Kalanyan, B.; Parsons, G. N.; Meyer, T. J. Stabilizing Small Molecules on Metal Oxide Surfaces Using Atomic Layer Deposition. Nano Lett. 2013, 13, 4802-4809.

(27) Hanson, K.; Losego, M. D.; Kalanyan, B.; Ashford, D. L.; Parsons, G. N.; Meyer, T. J. Stabilization of $\left[\mathrm{Ru}(\mathrm{bpy})_{2}\left(4,4^{\prime}-\right.\right.$ $\left(\mathrm{PO}_{3} \mathrm{H}_{2}\right)$ bpy $\left.)\right]^{2+}$ on Mesoporous $\mathrm{TiO}_{2}$ with Atomic Layer Deposition of $\mathrm{Al}_{2} \mathrm{O}_{3}$. Chem. Mater. 2013, 25, 3-5.

(28) Cai, N.; Moon, S. J.; Cevey-Ha, L.; Moehl, T.; Humphry-Baker, R.; Wang, P.; Zakeeruddin, S. M.; Gratzel, M. An Organic D- $\pi$-A Dye for Record Efficiency Solid-State Sensitized Heterojunction Solar Cells. Nano Lett. 2011, 11, 1452-1456.

(29) Chung, I.; Lee, B.; He, J.; Chang, R. P. H.; Kanatzidis, M. G. AllSolid-State Dye-Sensitized Solar Cells with High Efficiency. Nature 2012, 485, 486-490.

(30) Lee, M. M.; Teuscher, J.; Miyasaka, T.; Murakami, T. N.; Snaith, H. J. Efficient Hybrid Solar Cells Based on Meso-Superstructured Organometal Halide Perovskites. Science 2012, 338, 643-647.

(31) Desilvestro, H.; Bertoz, M.; Tulloch, S.; Tulloch, G. DyeSensitized Solar Cells, 1st ed.; EPFL Press: Lausanne, Switzerland, 2010; pp 207-249.

(32) Son, H.-J.; Prasittichai, C.; Mondloch, J. E.; Luo, L.; Wu, J.; Kim, D. W.; Farha, O. K.; Hupp, J. T. Dye Stabilization and Enhanced Photoelectrode Wettability in Water-Based Dye-Sensitized Solar Cells through Post-assembly Atomic Layer Deposition of $\mathrm{TiO}_{2}$. J. Am. Chem. Soc. 2013, 135, 11529-11532.

(33) Hausmann, D.; Becker, J.; Wang, S.; Gordon, R. G. Rapid Vapor Deposition of Highly Conformal Silica Nanolaminates. Science 2002, 298, 402-406.

(34) Cho, W.; Sung, K.; An, K.-S.; Lee, S. S.; Chung, T.-M.; Kim, Y. Atomic Layer Deposition of $\mathrm{Al}_{2} \mathrm{O}_{3}$ Thin Films Using Dimethylaluminum Isopropoxide and Water. J. Vac. Sci. Technol., A 2003, 21, 13661370.

(35) Kim, C. H.; Joo, T. Ultrafast Time-Resolved Fluorescence by Two Photon Absorption Excitation. Opt. Express 2008, 16, 2074220747.

(36) Rhee, H.; Joo, T. Noncollinear Phase Matching in Fluorescence Upconversion. Opt. Lett. 2005, 30, 96-98.

(37) Since $J-V$ plots were measured without masking, the photocurrent densities shown in figures (Figures 2 and 3 and Figures S4 and S7 in the Supporting Information) and tables (Table 1 and
Tables S1 and S3 in the Supporting Information) have been corrected downward by a factor of 1.15 to account for the error. It is conceivable that small errors in photovoltages remain. We have not attempted to correct for these.

(38) El-Zohry, A.; Orthaber, A.; Zietz, B. Isomerization and Aggregation of the Solar Cell Dye D149. J. Phys. Chem. C 2012, 116, 26144-26153.

(39) Burke, A.; Schmidt-Mende, L.; Ito, S.; Gratzel, M. A Novel Blue Dye for Near-IR 'Dye-Sensitised' Solar Cell Applications. Chem. Commun. 2007, 234-236.

(40) Wang, Z.-S.; Cui, Y.; Dan-oh, Y.; Kasada, C.; Shinpo, A.; Hara, K. 2,3-Disubstituted Thiophene-Based Organic Dyes for Solar Cells. J. Phys. Chem. C 2007, 111, 7224-7230.

(41) Lu, H.-P.; Tsai, C.-Y.; Yen, W.-N.; Hsieh, C.-P.; Lee, C.-W.; Yeh, C.-Y.; Diau, E. W.-G. Control of Dye Aggregation and Electron Injection for Highly Efficient Porphyrin Sensitizers Adsorbed on Semiconductor Films with Varying Ratios of Coadsorbate. J. Phys. Chem. C 2009, 113, 20990-20997.

(42) Yum, J.-H.; Jang, S.-R.; Humphry-Baker, R.; Gratzel, M.; Cid, J.J.; Torres, T.; Nazzeeruddin, Md. K. Effect of Coadsorbent on the Photovoltaic Performance of Zinc Pthalocyanine-Sensitized Solar Cells. Langmuir 2008, 24, 5636-5640.

(43) Hamann, T. W.; Farha, O. K.; Hupp, J. T. Outer-Sphere Redox Couples as Shuttles in Dye-Sensitized Solar Cells. Performance Enhancement Based on Photoelectrode Modification via Atomic Layer Deposition. J. Phys. Chem. C 2008, 112, 19756-19764.

(44) Li, T. C.; Góes, M. S.; Fabregat-Santiago, F.; Bisquert, J.; Bueno, P. R.; Prasittichai, C.; Hupp, J. T.; Marks, T. J. Surface Passivation of Nanoporous $\mathrm{TiO}_{2}$ via Atomic Layer Deposition of $\mathrm{ZrO}_{2}$ for SolidState Dye-Sensitized Solar Cell Applications. J. Phys. Chem. C 2009, $113,18385-18390$.

(45) Antila, L. J.; Heikkil, M. J.; Aumanen, V.; Kemell, M.; Myllyperki, P.; Leskel, M.; Korppi-Tommola, J. E. I. Suppression of Forward Electron Injection from $\mathrm{Ru}(\mathrm{dcbpy})_{2}(\mathrm{NCS})_{2}$ to Nanocrystalline $\mathrm{TiO}_{2}$ Film As a Result of an Interfacial $\mathrm{Al}_{2} \mathrm{O}_{3}$ Barrier Layer Prepared with Atomic Layer Deposition. J. Phys. Chem. Lett. 2010, 1, $536-539$.

(46) Antila, L. J.; Heikkilä, M. J.; Mäkinen, V.; Humalamäki, N.; Laitinen, M.; Linko, V.; Jalkanen, P.; Toppari, J.; Aumanen, V.; Kemell, M.; Myllyperkiö, P.; Honkala, K.; Häkkinen, H.; Leskelä, M.; KorppiTommola, J. E. I. ALD Grown Aluminum Oxide Submonolayers in Dye-Sensitized Solar Cells: The Effect on Interfacial Electron Transfer and Performance. J. Phys. Chem. C 2011, 115, 16720-16729.

(47) Chandiran, A. K.; Tetreault, N.; Humphry-Baker, R.; Kessler, F.; Baranoff, E.; Yi, C.; Nazeeruddin, M. K.; Grätzel, M. Subnanometer $\mathrm{Ga}_{2} \mathrm{O}_{3}$ Tunnelling Layer by Atomic Layer Deposition to Achieve $1.1 \mathrm{~V}$ Open-Circuit Potential in Dye-Sensitized Solar Cells. Nano Lett. 2012, 12, 3941-3947.

(48) Park, K.; Zhang, Q.; Garcia, B. B.; Zhou, X.; Jeong, Y.-H.; Cao, G. Effect of an Ultrathin $\mathrm{TiO}_{2}$ Layer Coated on Submicrometer-Sized $\mathrm{ZnO}$ Nanocrystallite Aggregates by Atomic Layer Deposition on the Performance of Dye-Sensitized Solar Cells. Adv. Mater. 2010, 22, 2329-2332.

(49) Lin, C.; Tsai, F.-Y.; Lee, M.-H.; Lee, C.-H.; Tien, T.-C.; Wang, L.-P.; Tsaib, S.-Y. Enhanced Performance of Dye-Sensitized Solar Cells by an $\mathrm{Al}_{2} \mathrm{O}_{3}$ Charge-Recombination Barrier Formed by LowTemperature Atomic Layer Deposition. J. Mater. Chem. 2009, 19, 2999-3003.

(50) Ganapathy, V.; Karunagaran, B.; Rhee, S.-W. Improved Performance of Dye-Sensitized Solar Cells with $\mathrm{TiO}_{2} /$ Alumina Core-Shell Formation Using Atomic Layer Deposition. J. Power Sources 2010, 195, 5138-5143.

(51) Prasittichai, C.; Hupp, J. T. Surface Modification of $\mathrm{SnO}_{2}$ Photoelectrodes in Dye-Sensitized Solar Cells: Significant Improvements in Photovoltage via $\mathrm{Al}_{2} \mathrm{O}_{3}$ Atomic Layer Deposition. J. Phys. Chem. Lett. 2011, 1, 1611-1615.

(52) Prasittichai, C.; Avila, J. R.; Farha, O. K.; Hupp, J. T. Systematic Modulation of Quantum (Electron) Tunneling Behavior by Atomic 
Layer Deposition on Nanoparticulate $\mathrm{SnO}_{2}$ and $\mathrm{TiO}_{2}$ Photoanodes. J. Am. Chem. Soc. 2013, 135, 16328-16331.

(53) Bisquert, J. Theory of the Impedance of Electron Diffusion and Recombination in a Thin Layer. J. Phys. Chem. B 2002, 106, 325-333.

(54) Katz, M. J.; Vermeer, M. J. D.; Farha, O. K.; Pellin, M. J.; Hupp, J. T. Effects of Adsorbed Pyridine Derivatives and Ultrathin AtomicLayer-Deposited Alumina Coatings on the Conduction Band-Edge Energy of $\mathrm{TiO}_{2}$ and on Redox-Shuttle-Derived Dark Currents. Langmuir 2013, 29, 806-814.

(55) Jeong, N. C.; Son, H.-J.; Prasittichai, C.; Lee, C. Y.; Jensen, R. A.; Farha, O. K.; Hupp, J. T. Effective Panchromatic Sensitization of Electrochemical Solar Cells: Strategy and Organizational Rules for Spatial Separation of Complementary Light Harvesters on High-Area Photoelectrodes. J. Am. Chem. Soc. 2012, 134, 19820-19827.

(56) Hara, K.; Sato, T.; Katoh, R; Furube, A.; Ohga, Y.; Shinpo, A.; Suga, S.; Sayama, K.; Sugihara, H.; Arakawa, H. Molecular Design of Coumarin Dyes for Efficient Dye-Sensitized Solar Cells. J. Phys. Chem. B 2003, 107, 597-606.

(57) Kay, A.; Gratzel, M. Artificial Photosynthesis. 1. Photosensitization of Titania Solar Cells with Chlorophyll Derivatives and Related Natural Porphyrins. J. Phys. Chem. 1993, 97, 6272-6277.

(58) Koops, S. E.; Barnes, P. R. F.; O’Regan, B. C.; Durrant, J. R. Kinetic Competition in a Coumarin Dye-Sensitized Solar Cell: Injection and Recombination Limitations upon Device Performance. J. Phys. Chem. C 2010, 114, 8054-8061.

(59) Bunz, U. H. F.; Levitus, M.; Schmieder, K.; Ricks, H.; Shimizu, K. D.; Garcia-Garibay, M. A. Steps To Demarcate the Effects of Chromophore Aggregation and Planarization in Poly(phenyleneethynylene)s. 1. Rotationally Interrupted Conjugation in the Excited States of 1,4-Bis(phenylethynyl)benzene. J. Am. Chem. Soc. 2001, 123, 4259-4265.

(60) Elsaesser, T.; Kaiser, W. Vibrational and Vibronic Relaxation of Large Polyatomic Molecules in Liquids. Annu. Rev. Phys. Chem. 1991, $42,83-107$.

(61) Hintschich, S. I.; Dias, F. B.; Monkman, A. P. Dynamics of Conformational Relaxation in Photoexcited Oligofluorenes and Polyfluorene. Phys. Rev. B 2006, 74, 045210.

(62) To resolve the kinetics resulting from electron injection, we averaged the time coefficients according to the amplitude-averaged decay time model. ${ }^{61}$ The average time coefficients are summarized in Table S5 (see the Supporting Information). The electron injection yields were determined using the following equation: $\Phi_{\mathrm{inj}}=$ $\left[\left\{\tau_{\mathrm{OrgD}\left(8 \mathrm{TiO}_{2} \text { or } 10 \mathrm{Al}_{2} \mathrm{O}_{3} \mathrm{ALD}\right)}\right\} /\left\{\tau_{\mathrm{OrgD}(\mathrm{free})}\right\}\right] \times 100$

(63) Lu, H.-P.; Tsai, C.-Y.; Yen, W.-N.; Hsieh, C.-P.; Lee, C.-W.; Yeh, C.-Y.; Diau, E. W.-G. Control of Dye Aggregation and Electron Injection for Highly Efficient Porphyrin Sensitizers Adsorbed on Semiconductor Films with Varying Ratios of Coadsorbate. J. Phys. Chem. C 2009, 113, 20990-20997. 